\title{
CORRIGENDUM
}

\section{Activation of the HIF pathway in childhood ALL, prognostic implications of VEGF}

S Wellmann, M Guschmann, W Griethe, C Eckert, Av Stackelberg, C Lottaz, E Moderegger, HG Einsiedel, K-U Eckardt, G Henze and K Seeger

Leukemia (2004) 18, 1164. doi:10.1038/sj.leu.2403394

Correction to: Leukemia (2004) 18, 926-933. doi: 10.1038/sj.leu.2403332
It has been identified that the name of the author Av Stackelberg was misspelled in the above article. The correct name is reproduced below:

A von Stackelberg

The authors apologise for any confusion this might have caused. 